themselves, and have no experience of how we cope with day-today events. It is all very well to say we cannot read letters on a chart, but if we can do proper jobs and lead normal lives, does that really matter ? The work now being carried out to establish the cause, and, I hope, a remedy, will benefit those who follow us immensely. It is surely equally important to give advice and encouragement to young albinos and their families and to ensure that their chance to follow pursuits that they are quite capable of is not denied to them through the application of erroneous assumptions.

\section{Clinical details of the author*}

Date of birth: 24 December 1944. Tyrosinase-negative oculocutaneous albino.

Complaint-Dazzling in the light and strabismus from birth. Nystagmus.

Family history-An only child, with no definite history of albinism in the family; own two children normally pigmented.

Present condition-Skin: milk-white and pink, folded, rough, hyperkeratotic. Hair: snow white. Irides: translucent. Fundi: "albinotic." Colour vision: red deviation. ${ }^{1}$ Visual-evoked response: responses over right hemisphere seem to be deficient in their early components when compared with responses measured over the left hemisphere. ${ }^{2}$
Refraction-Right: $+3 \cdot 25 \mathrm{D}$ sphere $+2.75 \mathrm{D}$ cylinder $85^{\circ}=6 / 60+$; left: $+3.00 \mathrm{D}$ sphere $+3.00 \mathrm{D}$ cylinder $85^{\circ}=6 / 60+$.

Correction-Wore tinted glasses, at first blue, then brownish. In 1961 he was referred to contact-lens clinic at Moorfields and fitted with haptic painted occlusive lenses, but since there was "no substantial improvement in vision," these were abandoned. Nevertheless, in 1966 a further attempt was made, and some success obtained with blue-tinted haptic lenses, particularly for reading-presumably by slowing down the rate of nystagmus. Now, however, he prefers to use corrective photochromic lenses, which particularly help his photophobia.-W O G TAYLOR (senior consultant ophthalmologist, retired, Ayr).

The author would be very pleased to discuss this subject with anyone who cared to contact him at 20 Woolfield, Sandy, Bedfordshire, telephone number Sandy 80138.

Requests for reprints should be addressed to Dr W O G Taylor, 16 Ronaldshaw Park, Ayr, Scotland.

\section{References}

${ }^{1}$ Pickford, R W, and Taylor, W O G, British fournal of Ophthalmology, $1968,52,640$.

${ }^{2}$ Creel, D, Witkop, C J, jun, and King, R A, Investigative Ophthalmology, $1974,13,430$.

(Accepted 6 November 1978)

\title{
Management and outcome of winter upper respiratory tract infections in children aged $0-9$ years
}

\author{
N C H STOTT \\ British Medical fournal, 1979, 1, 29-31
}

\section{Summary and conclusions}

Age-specific incidences for upper respiratory tract infections in children from a new-town population during 1975-7 were studied, and 965 consecutive upper respiratory tract infections in children aged under 10 during two winters were analysed in detail. Significantly different management plans made by seven doctors did not correlate with the clinical outcome as judged by complications, recall rates, and demand for treatment for similar episodes in the future. Two hundred and thirty-two children $(24 \%)$ returned for another consultation for the same episode of upper repiratory tract infection. The main reason for these repeat consultations

\footnotetext{
Welsh National School of Medicine, General Practice Unit, Maelfa, Llanedeyrn, Cardiff CF3 7PN
}

N C H STOTT, BSC, MRCPED, senior lecturer in general practice seemed to be that parental expectations about the natural history of the illness were not fulfilled.

More realistic parental expectations might be set and safer clinical standards maintained if doctors warned parents about symptoms such as cough and occasional diarrhoea or vomiting that are commonly associated with upper respiratory tract infections in children.

\section{Introduction}

The relation between the management of acute upper respiratory tract infection and the clinical outcome continues to be controversial, ${ }^{1}$ despite several controlled trials in recent years. ${ }^{2-5}$ Nevertheless, few family doctors seem to be aware of complication rates or recall rates in their patients after an upper respiratory tract infection, perhaps because it is commonly assumed that they all get better without mishap. Even Fry, in his classical description of the catarrhal child, ${ }^{6}$ failed to measure the immediate outcome of the various syndromes because he was most concerned with their natural history over a longer time scale.

I aimed at relating the outcome of acute upper respiratory tract infections in children to the management plans made by seven family doctors based in a health centre who attended to patients from the same new estate. 


\section{Methods}

Analysis of clinical management and outcome was restricted to all patients aged below 10 years who presented to the seven half-time principals in the practice during four winter months (November to February) in both 1975 and 1976. Detailed analysis was confined to winter upper respiratory tract infections to reduce possible confusion with spring and summer allergic symptoms and to capture the seasonal period of peak incidence.

All new episodes of illness were entered on to problem lists and coded by clerks in the study practice. The methods used to improve the quality of recorded information have been described elsewhere, ${ }^{i}$ but consensus agreement on the minimal criteria to justify a diagnosis of tonsillitis, coryza, or non-specific upper respiratory tract infection has proved difficult, so the analysis of clinical outcome is concerned with all upper respiratory tract infections rather than a spurious attempt to deal with subdivisions that reflect variations of labelling more than specific disease processes. In another study ${ }^{3}$ there was a high level of agreement between the doctors about the presence or absence of chest signs, thus "upper respiratory tract infection" was a real entity in the study practice, albeit an umbrella for several less clear subdivisions. Patients whose diagnosis at first contact was acute otitis media are not included in the present series, but minor degrees of injection of the ear-drums associated with a dominant diagnosis of upper respiratory tract infection are included. With the help of clerks, I extracted outcome information from the clinical records. (Further details of this procedure are available on request.)

\section{Results}

The four diagnoses constituting the total figures for upper respiratory tract infections in the practice are shown in table $I$.

\section{MANAGEMENT}

Detailed analysis of 965 new episodes of upper respiratory tract infection during November to February in children aged below 10 years showed that the patients attending each of the seven doctors were homogeneous in terms of age, medical history, and time spent on the practice list, but doctors' management of the upper respiratory tract infections varied significantly (table II). Overall, about $40^{\circ}$ o of children with upper respiratory tract infection received antibiotics, $30 \%$ cough mixtures or decongestants, or both, and $30^{\circ}$ advice alone. Other proprietary preparations such as aspirin or paracetamol are not included because though widely used, they are rarely prescribed. Other remedies were used too infrequently to merit analysis. Patients given a prescription usually had it for either an antibiotic or a cough mixture or decongestant, or both; both were rarely prescribed.

\section{OUTCOME}

Table II shows crude complication rates, recall rates, and the number of patients returning for further treatment for upper respiratory tract infections within six months. There were no significant differences between the seven clinicians. Even more important is an absence of intercorrelation between the prescribing patterns and complication rate, recall rate, or further infection rate. The only significant negative correlation was between the number of those aged from 5 to 9 years who were seen and the recall rate $(P<0.05)$, but this is of doubtful importance because elimination of doctor $\mathrm{A}$ reduced the correlation to insignificant levels, and he saw few patients.

During the six months after the initial episode of illness $30 \%$ of patients had one more upper respiratory tract infection, $11 \%$ had two more episodes, and less than $5 \%$ had three or more episodes. Detailed examination of the records of the seven patients who returned for four or more new episodes of upper respiratory tract infection during six months showed that every one came from a disturbed or fiercely possessive background. None of them had been referred for tonsillectomy or adenoidectomy, none had developed a secretory otitis media, and only two were atopic subjects.

TABLE I-Upper respiratory tract infections (URTIs): age-specific incidences per thousand

\begin{tabular}{|c|c|c|c|c|c|c|c|c|c|c|c|}
\hline \multirow{2}{*}{$\underset{(\text { years) }}{\text { Age }}$} & \multirow[t]{2}{*}{ Year } & \multicolumn{2}{|c|}{ All URTI } & \multicolumn{2}{|c|}{ Coryza } & \multicolumn{2}{|c|}{$\begin{array}{c}\text { Non-specific } \\
\text { URTI }\end{array}$} & \multicolumn{2}{|c|}{$\begin{array}{c}\text { Tonsillitis or pharyngitis } \\
\text { (or both) }\end{array}$} & \multicolumn{2}{|c|}{ Cough } \\
\hline & & No & Rate & No & Rate & No & Rate & No & Rate & No & Rate \\
\hline $0-4$ & $\begin{array}{l}1975 \\
1976 \\
1977\end{array}$ & $\begin{array}{l}1368 \\
1243 \\
1075\end{array}$ & $\begin{array}{l}1169 \cdot 2 \\
1208.0 \\
1247 \cdot 1\end{array}$ & $\begin{array}{l}91 \\
90 \\
53\end{array}$ & $\begin{array}{l}77.8 \\
87.5 \\
61.5\end{array}$ & $\begin{array}{l}661 \\
667 \\
562\end{array}$ & $\begin{array}{l}565 \cdot 0 \\
648 \cdot 2 \\
652 \cdot 0\end{array}$ & $\begin{array}{l}292 \\
220 \\
248\end{array}$ & $\begin{array}{l}249 \cdot 6 \\
213.8 \\
287.7\end{array}$ & $\begin{array}{l}324 \\
266 \\
212\end{array}$ & $\begin{array}{l}276.9 \\
258.5 \\
245.9\end{array}$ \\
\hline $5-9$ & $\begin{array}{l}1975 \\
1976 \\
1977\end{array}$ & $\begin{array}{l}828 \\
966 \\
834\end{array}$ & $\begin{array}{l}718 \cdot 1 \\
759 \cdot 4 \\
625 \cdot 7\end{array}$ & $\begin{array}{l}19 \\
18 \\
19\end{array}$ & $\begin{array}{l}16 \cdot 5 \\
14 \cdot 1 \\
14 \cdot 2\end{array}$ & $\begin{array}{l}323 \\
451 \\
345\end{array}$ & $\begin{array}{l}280 \cdot 1 \\
354 \cdot 6 \\
258.8\end{array}$ & $\begin{array}{l}306 \\
348 \\
293\end{array}$ & $\begin{array}{l}265.4 \\
273 \cdot 6 \\
219.8\end{array}$ & $\begin{array}{l}180 \\
149 \\
177\end{array}$ & $\begin{array}{l}156 \cdot 1 \\
117.1 \\
132.8\end{array}$ \\
\hline $10-14$ & $\begin{array}{l}1975 \\
1976 \\
1977\end{array}$ & $\begin{array}{l}283 \\
326 \\
308\end{array}$ & $\begin{array}{l}442 \cdot 2 \\
437.0 \\
377 \cdot 9\end{array}$ & $\begin{array}{r}9 \\
20 \\
7\end{array}$ & $\begin{array}{r}14 \cdot 1 \\
26 \cdot 8 \\
8 \cdot 6\end{array}$ & $\begin{array}{l}133 \\
159 \\
137\end{array}$ & $\begin{array}{l}207.8 \\
213.1 \\
168.1\end{array}$ & $\begin{array}{r}95 \\
115 \\
119\end{array}$ & $\begin{array}{l}148 \cdot 4 \\
143 \cdot 2 \\
146 \cdot 0\end{array}$ & $\begin{array}{l}46 \\
32 \\
45\end{array}$ & $\begin{array}{l}71.9 \\
42.9 \\
55.2\end{array}$ \\
\hline
\end{tabular}

TABLE II-Management and outcome of upper respiratory tract infection (URTI) during November-February 1975-6 and 1976-7 in children aged under 10 years. Percentages are given in parentheses

\begin{tabular}{|c|c|c|c|c|c|c|c|}
\hline Doctor & $\begin{array}{c}\text { No } \\
\text { seen }\end{array}$ & $\begin{array}{c}\text { Cough } \\
\text { suppressant }\end{array}$ & Antibiotics & $\begin{array}{c}\text { Advice } \\
\text { alone }\end{array}$ & Complication & Recall & $\begin{array}{l}\text { Further URTI } \\
\text { within } 6 \text { months }\end{array}$ \\
\hline \multicolumn{8}{|c|}{ Children aged 0-4 years } \\
\hline $\begin{array}{l}\text { A } \\
\text { B } \\
\text { C } \\
\text { D } \\
\text { E } \\
\text { F } \\
\text { G } \\
\end{array}$ & $\begin{array}{r}37 \\
71 \\
79 \\
97 \\
95 \\
80 \\
103 \\
\end{array}$ & $\begin{array}{r}4(11) \\
13(18) \\
13(16) \\
56(57) \\
22(23) \\
32(40) \\
35(34) \\
\end{array}$ & $\begin{array}{r}6(16) \\
42(59) \\
42(53) \\
35(36) \\
38(40) \\
16(20) \\
46(45) \\
\end{array}$ & $\begin{array}{l}26(70) \\
17(24) \\
29(36) \\
13(13) \\
32(33) \\
29(36) \\
26(25) \\
\end{array}$ & $\begin{array}{r}7(19) \\
11(15) \\
9(11) \\
17(18) \\
16(17) \\
13(16) \\
24(23) \\
\end{array}$ & $\begin{array}{c}2(5) \\
11(15) \\
6(8) \\
4(4) \\
3(3) \\
10(13) \\
7(7) \\
\end{array}$ & $\begin{array}{l}17(46) \\
35(49) \\
39(49) \\
49(51) \\
44(46) \\
38(47) \\
44(43)\end{array}$ \\
\hline \multirow[t]{2}{*}{ All doctors } & 562 & $175(31)$ & $225(40)$ & $172(31)$ & $97(17)$ & $43(8)$ & $266(47)$ \\
\hline & Significance & $\mathrm{P}<0.001$ & $P<0.01$ & $\mathrm{P}<0.001$ & NS & NS & NS \\
\hline \multicolumn{8}{|c|}{ Children aged 5-9 years } \\
\hline $\begin{array}{l}\text { A } \\
\text { B } \\
\text { C } \\
\text { D } \\
\text { E } \\
\text { F } \\
\text { G } \\
\end{array}$ & $\begin{array}{l}28 \\
51 \\
68 \\
55 \\
57 \\
98 \\
46 \\
\end{array}$ & $\begin{array}{r}0(0) \\
5(10) \\
30(44) \\
33(60) \\
8(14) \\
32(33) \\
12(26) \\
\end{array}$ & $\begin{array}{r}8(29) \\
25(49) \\
11(16) \\
23(42) \\
29(51) \\
35(36) \\
17(37) \\
\end{array}$ & $\begin{array}{r}17(61) \\
13(25) \\
20(29) \\
4(7) \\
19(33) \\
30(30) \\
17(37) \\
\end{array}$ & $\begin{array}{r}3(11) \\
11(22) \\
9(13) \\
10(18) \\
8(14) \\
14(14) \\
9(20) \\
\end{array}$ & $\begin{array}{l}5(18) \\
4(8) \\
5(7) \\
3(5) \\
3(5) \\
5(5) \\
3(7) \\
\end{array}$ & $\begin{array}{l}13(46) \\
21(41) \\
25(37) \\
25(45) \\
22(39) \\
42(43) \\
24(52) \\
\end{array}$ \\
\hline \multirow[t]{2}{*}{ All doctors } & 403 & $120(30)$ & $148(37)$ & $120(30)$ & $64(16)$ & $28(7)$ & $172(43)$ \\
\hline & Significance & $\mathrm{P}<0.001$ & $P<0.05$ & $P<0.001$ & NS & NS & NS \\
\hline
\end{tabular}




\section{DETAILED ANALYSIS OF RETURNING PATIENTS}

The figure shows the immediate outcome in the 965 patients with acute upper respiratory tract infections.

Return consultations-Seventy-one routine return consultations ( $7 \%$ of total) were initiated by either doctor or patient, but treatment was not changed.

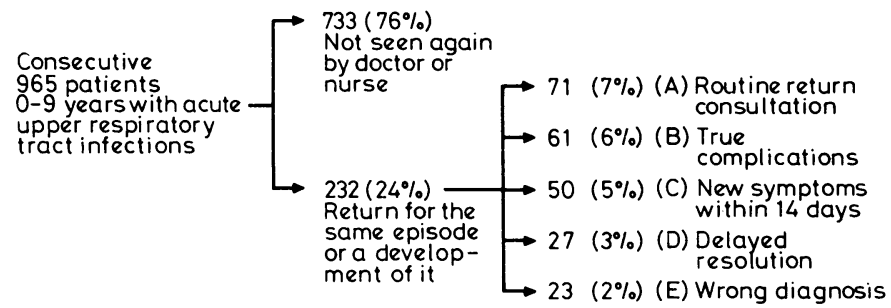

Immediate outcome of winter upper respiratory tract infections in patients aged 0-9 years who presented consecutively to seven primary-care physicians.

True complications-Sixty-one traditional complications $(6 \%)$ were diagnosed as follows (numbers in parentheses): acute otitis media (31); lower respiratory tract infections (22); more toxic or ill (2); penicillin allergy (2); acute nephritis (1); febrile convulsion (1); middle respiratory tract infection (1); and otitis externa (1). In most of the children with acute otitis media the condition was diagnosed within five days of the initial episode of upper respiratory tract infection, and in 11 of them antibiotic treatment had been started before the diagnosis of an ear infection was made. None of the children with lower respiratory tract infections needed to be admitted to hospital, and five of them had been given an antibiotic when upper respiratory tract infection was initially diagnosed, which suggested that treatment had not halted progress downwards of the disease. The two patients who became more generally ill and the one who developed acute nephritis were all receiving antibiotic treatment before the complications developed. None needed to be admitted to hospital.

New symptoms-Fifty new symptoms developed within two weeks of the primary diagnosis $(5 \%)$ and were probably attributable to the primary disease process. They comprised the following (numbers in parentheses): cough (13); diarrhoea and vomiting (9); bronchospasm (8); vomiting (5); macular rash at three to seven days (4); abdominal pain (3); aphthous ulcers (2); other symptoms (6). Development of these symptoms was not affected by initial antibiotic treatment.

Delayed resolution-Twenty-seven patients $(3 \%)$ had persistent primary symptoms two weeks after diagnosis without specific complications, the commonest complaint being persistent cough.

Wrong diagnosis-Twenty-three wrong diagnoses $(2 \%)$ were enanthemas, comprising: measles (6); mumps (3); chickenpox (1); rubella (1); and tonsillitis (12). Five of the six patients who developed measles had been given antibiotics at the initial consultation, presumably because the children looked ill in the catarrhal phase. A mild exudate on non-inflamed tonsils was a cause of confusion in the cases of mumps.

\section{Discussion}

The large proportion of children $(24 \%)$ who were seen again for the same episode of illness or a complication of it was surprising because most workers regard the common upper respiratory tract infections as fairly free of complications. Fry, ${ }^{8}$ when discussing coughs, colds, and catarrhal illnesses, says "most of these children recover quickly with simple measures," but neither he nor Hodgkin ${ }^{9}$ give any quantitative assessment of the return rates or complication rates. Illingworth ${ }^{10}$ and Jolly ${ }^{11}$ are equally vague, and their reassuring generalisations seem to be based on little except personal impressions. While only 61 of the children in this study $(6 \%)$ developed medical complications, why did 232 patients $(24 \%)$ returned for second appointments (figure)?

The doctors' widely differing prescribing and advising habits did not correlate with the clinical outcome judged by complica- tion rates, return rates, and reinfection rates (table II). This may be due to lack of sensitivity in the outcome of indices chosen, but it is reassuring to know that doctors who prescribe antibiotics for $20 \%$ of upper respiratory tract infections in children have similar crude complication rates to those who give antibiotics to $60 \%$ of such cases. The proportion of patients returning for further treatment for upper respiratory tract infections within six months was similar for each doctor's patients, suggesting that the mothers' decision to seek help for future upper respiratory infection was either influenced uniformly by each of the doctors or was not influenced by the doctors at all. Marsh ${ }^{12}$ has shown that patients can be educated to reduce demands for minor illnesses, but his study was short and further studies are needed to establish the reliability of his important results, but the fact that only $30 \%$ of patients in the present series left without a prescription is a cause for concern.

The results suggest that second consultations for children with uncomplicated upper respiratory tract infections are often initiated by parents because the illness has not followed its expected course. Doctors often encourage mothers to return "if the child doesn't get better," or they use vague, reassuring generalisations such as "it is only a cold and will be better in a few days." Indeed, the last sentiment is commonplace in paediatric texts, yet the study shows that this is only partly true, and $24 \%$ of parents declared their disquiet by seeking further consultations when their children's symptoms persisted or new ones developed. Perhaps more realistic parental expectations may be set and safer clinical standards maintained if doctors warn mothers that children may cough for over two weeks after an uncomplicated upper respiratory tract infection and that occasional diarrhoea or vomiting are also commonly associated with these ailments. Provided that the child is taking fluids and remains generally well, such symptoms do not merit a further consultation, indeed they are healthy bodily responses to infection. Unfortunately, we cannot predict accurately which patients with upper respiratory tract infection will cough longest or are most likely to have gastrointestinal symptoms, but the results suggest that those whose dominant presenting symptom is cough are particularly at risk.

Doctors need to pay particular attention to their influence on patients' expectations and future decisions to seek help, ${ }^{13}$ but full understanding of the clinical information published in this study will come only when similar work from other practices allows wider comparisons to be drawn.

I thank Mrs Margaret Jones and her team for their help in extracting and analysing data for this project; my six colleagues in the general practice unit for their continuing support and co-operation; and $\mathrm{Dr}$ Robert West for statistical advice.

Further details of procedures used in Methods and Results sections are available from the author.

\section{References}

${ }^{1}$ Howie, J G R, et al, fournal of the Royal College of General Practitioners, $1971,21,657$.

2 Gordon, M, Lovell, S, and Dugdale, A E, Medical fournal of Australia, 1974, 1, 304.

${ }^{3}$ Stott, N C H, and West, R R, British Medical fournal, 1976, 2, 556.

4 Taylor, B, et al, British Medical fournal, 1977, 2, 552.

${ }^{5}$ Howie, J G R, British Medical fournal, 1976, 2, 1061.

${ }^{6}$ Fry, J, The Catarrhal Child. London, Butterworth, 1966.

${ }^{7}$ Stott, N C H, and Davis, R H, Fournal of the Royal College of General Practitioners, 1975, 25, 888 .

${ }^{8}$ Fry, J, Common Diseases. Lancaster, MTP, 1974.

${ }^{9}$ Hodgkin, K, Towards Earlier Diagnosis. Edinburgh, Livingstone, 1974.

10 Illingworth, R S, Common Symptoms of Disease in Children. Oxford, Blackwell, 1975.

${ }^{11}$ Jolly, H, Diseases of Children. Oxford, Blackwell Scientific Publications, 1976.

${ }^{12}$ Marsh, G N, British Medical fournal, 1977, 2, 1267.

13 Stott, N C H, and Davis, R H, fournal of the Royal College of General Practitioners. In press.

(Accepted 24 October 1978) 